Copyright 2010 AIP Publishing. This article may be downloaded for personal use only. Any other use requires prior permission of the author and AIP Publishing. The following article appeared as: Martinuk, M., Moll, R.F. \& Kotlicki, A. (2010). Teaching introductory physics with an environmental focus. The Physics Teacher, 48(6), 212-214, and may be found at http://dx.doi.org/10.1119/1.3479725 


\section{Teaching Introductory Physics with an Environmental Focus}

Mathew "Sandy" Martinuk, Rachel F. Moll, and Andrzej Kotlicki, University of British Columbia, Vancouver, BC

$\mathrm{T}$ Throughout North America the curriculum of introductory physics courses is nearly standardized. In 1992, Tobias wrote that four texts dominate $90 \%$ of the introductory physics market ${ }^{1}$ and current physics education research is focusing on how to sustain educational reforms. ${ }^{2}$ The instructional team at the University of British Columbia (UBC) recently implemented some key curriculum and pedagogical changes in Physics 100, their algebra-based introductory course for non-physics majors. These changes were aimed at improving their students' attitudes toward physics and their ability to apply physics concepts to useful real-life situations. In order to demonstrate that physics is relevant to real life, a theme of energy and environment was incorporated into the course.

Since the 1970s physics instructors have turned to realworld examples in order to motivate physics learners. ${ }^{3-6}$ In particular, connections to ecological crisis ${ }^{7-10}$ have been viewed as opportunities to not only make physics relevant, but to motivate students by engaging them in investigating a problem that is impacting both their day-to-day lives and their future. Today, interdisciplinarity is more the norm than the exception in universities, and thus the notion of a physics course has broadened somewhat. Despite this fact, the number of examples of environmentally relevant physics curricula for science majors ${ }^{10,11}$ in recent literature is low. This paper will describe how an environmental theme was incorporated into UBC's Physics 100 course and will outline current research that is being conducted in order to evaluate the impact of these changes on both student problem-solving skills and attitudes.

\section{The new Physics 100}

Physics 100 at the University of British Columbia is a noncalculus-based introductory physics course offered to science students who require a physics credit to complete their degree but who did not take senior high school physics. Students of Physics 100 are typically enrolled in pre-med, biology, human kinetics, or environmental science programs. There are also some arts students who choose Physics 100 as their required science credit. It is a large, lecture-style course that divides 700 students into three sections, each taught by a different instructor. The lecture is supported with weekly labs and tutorials, and students are assessed on their performance in the lab, participation in lecture, graded tutorial problems, midterm, final exam, and a final project. Changes to the course to make physics more relevant to students' everyday life experiences through connections to energy and the environment were first implemented in 2007 and were incorporated into most aspects of the course.

This course is now taught with strong connections to realworld examples of conservation of energy, energy consumption, and sustainability. While some introductory courses attempt to engage students by discussing advanced topics such as relativity, cosmology, and quantum mechanics, students may have difficulty perceiving how these topics impact their everyday lives. The changes to the Physics 100 course are designed to make explicit connections between course materials and everyday physics in order to increase students' belief in the relevance of physics to the real world and develop their problem-solving skills in order to be able to apply their physics knowledge outside the classroom.

For example, the concepts of conservation of energy are explored using the context of home heating and the Earth's energy balance. Kinematics is taught in the context of transportation and associated energy consumption and fuel efficiency, drawing connections to earlier ideas of energy and environmental impact. Basic concepts in electricity such as voltage, current, and resistance are covered with examples like home wiring, transmission lines, and electrical energy consumption. These real-world connections are reinforced through weekly tutorials, which require students to apply physics to contextrich $^{12}$ real world problems. Despite being conducted with standard simplified laboratory gear, the lab experiments are also contextualized using analogies to real-world examples.

Another important change to the course was the incorporation of a final project where students work in small groups to prepare a presentation on a topic of their choice related to the course. Students were asked to quantitatively model and estimate an answer to a scientific question. Past projects have endeavored to estimate the energy savings that would result if all households in the province switched from incandescent light bulbs to compact fluorescent lights, the greenhouse gas savings due to ridership on the local rapid transit system, and the energy benefits of paying bills online rather than by paper mail.

These extensive changes were supported by making a substantial effort to train the course's teaching assistants (TAs) to encourage conceptual understanding and real-world connections in their students. Weekly meetings were conducted between the faculty and the TAs to ensure open communication. In addition, the TAs' teaching skills were developed through a mentor TA program, where experienced TAs were available to train and support their peers. 


\section{Impacts of course changes}

An ongoing program of quantitative and qualitative research is investigating the results of course innovations in two major areas: student attitudes toward physics and student problem-solving skills.

Student attitudes were measured using the Colorado Learning Attitudes about Science Survey (CLASS). ${ }^{13}$ This survey was administered as a pre-/post-survey in 2006 prior to the course changes, and then again in 2007. The CLASS survey uses 42 Likert-style $^{14}$ questions to measure student attitudes about physics and learning. Student responses are compared to an expert response to determine the percentage of items for which the student agrees with the expert response, termed the $\%$ favorable score. For each student, the $\%$ shift is calculated by subtracting the initial $\%$ favorable score from the final \% favorable score.

The items on the survey are grouped into eight categories, one of which is a collection of four questions around the theme of real-world connections in physics. Despite the introduction of the course changes in 2007, there was no statistical difference between the average \% shift scores in this category in 2006 and 2007. Interviews conducted after the 2007 course revealed several possible reasons for the failure of course innovations to improve students' attitudes in this area. One common student comment was that several of the major topics in the course used real-world examples that weren't compelling to the student population. For example, while students were familiar with environments where the physics of home heating is important, most of them have never paid a heating bill and were therefore not interested in the details of heat loss. Student comments also highlighted that examples based on driving were not directly relevant since a significant proportion of the students don't drive; the scarcity of oncampus parking combined with free transit passes means that the majority of Physics 100 students commute by bus. These results point to significant differences between the instructors and students in their perception of the real-world relevance of problems, which have prompted a more detailed investigation that compares students' and instructors' perceptions of the real-world examples that were used in the 2008 course.

Student interviews did reveal that real-life connections to physics concepts were most effectively achieved through the final project. Approximately half of those interviewed cited the final project as a strong motivator to make real-world connections, and one student said: "It [the final project] forced us to think about how we can apply [physics]. I thought about it for a long time and for that while that (AU: wording correct?) we were trying to come up with a topic I kept thinking about everything that related ... That week everything that I looked at was like physics, physics, physics." To follow up, a pre-/posttest of the students' ability to problem solve in a real-world context was also administered this year.

The CLASS survey did find significant differences in one category of student attitudes related to problem solving in physics. Two of the items in the problem-solving categories
Table I. Two items from the Colorado Learning Attitudes about Science Survey that demonstrated significant gains in the transformed course (2007) compared to 2006.

\begin{tabular}{|l|c|c|}
\hline \multicolumn{2}{|c|}{ \% shift in favorable responses } \\
\multicolumn{2}{|l|}{2006} & 2007 \\
\hline $\begin{array}{l}\text { Q34 - I can usually figure out a way } \\
\text { to solve physics problems }\end{array}$ & $-\mathbf{2 6 \%}$ & $\mathbf{1 5 \%}$ \\
\hline $\begin{array}{l}\text { Q40 - If I get stuck on a physics } \\
\text { problem, there is no chance l'll figure } \\
\text { it out on my own }\end{array}$ & $-\mathbf{2 9 \%}$ & $\mathbf{1 0 \%}$ \\
\hline
\end{tabular}

of the CLASS survey (items 34 and 40, listed below in Table I) showed a significantly higher \% shift in 2007 than in 2006. Follow-up interviews probed the impact of course changes on students' responses to these statements and their attitudes toward problem solving in general. The majority of students interviewed mentioned group work when prompted with the CLASS statements, and stated or implied that the tutorial structure, where students work in groups to solve context-rich problems, helped to develop their problem-solving skills. This implication seems to contradict other research that shows context-rich tutorials do not have an impact on students' attitudes about problem solving. ${ }^{15}$ The connection between group work in tutorials and student attitudes will be investigated in future research.

In addition to improving student attitudes, the Physics 100 instructors wanted to enable their students to apply their physics knowledge to real-world situations. Inspired by the work of Adams, ${ }^{16}$ we conceptualized this capability in terms of problem-solving skills. By using problems with complex solutions but low content knowledge requirements, Adams has shown that skill in problem solving can be broken down into a number of component skills. A multiple-choice instrument is currently under development that assesses individual students' ability to apply physics to novel situations by assessing their component problem-solving skills with a pre- and post-test. This will be used to further probe the development of students' problem-solving skills in this course.

Outside of the measures used in this study, the impact of course changes were felt by both instructors and students. The instructors reflected that the course changes created a more positive learning atmosphere and that it was more enjoyable to teach. Student evaluations of the course and personal feedback included many more positive comments than when the course was taught in a traditional way.

Curriculum and pedagogical changes to introductory physics for science majors may help to improve student problem-solving skills and attitudes toward physics. However, results from our research into the changes have illustrated the importance of choosing real-world examples that are relevant to the student population. The final project appears to have had the most significant impact on student attitudes because students appreciated the opportunity to direct and apply their own learning and to make their own connections between course content and their everyday lives. Context-rich tutorials 
and group work may be beneficial to student problem-solving skills, and future work will endeavor to further study this relationship using relevant real-world contexts with environmental themes.

\section{References}

1. S. Tobias, Revitalizing Undergraduate Science: Why some things work and most don't. An occasional paper on neglected problems in science education (Research Corp, Tucson, AZ, 1992).

2. S. J. Pollock and N. D. Finkelstein, "Sustaining educational reforms in introductory physics," Phys. Rev. ST Phys. Educ. Rev. 4, 101010 (2008).

3. R. D. Porter, "Phenomenological physics: Maine Township H.S. West style," Phys. Teach. 10, 193-195 (April 1972).

4. E. C. Holton, "Editorial: Issues for the seventies," Phys. Teach. 8, 229-232 (May 1970).

5. T. Liao and E. J. Piel, "Let's get relevant," Phys. Teach. 8, 74-82 (Feb. 1970).

6. D. N. Arion, K. M. Crosby, and E. A. Murphy, "Case-study experiments in the introductory physics curriculum," Phys. Teach. 38, 373-376 (Sept. 2000).

7. D. J. Cowan, "Environmental topics in an undergraduate physics curriculum," Am. J. Phys. 40, 1748-1756 (Dec. 1972).

8. S. F. Singer, "Education for today's ecological crisis," Sci. Educ. 54, 349-358 (Oct.-Nov. 1970).

9. R. Gerson, "Experience with an environment-related physics course," Phys. Teach. 11, 236-237 (April 1973).

10. J. M. Pratte, "Engaging physics students using environmental lab modules," Phys. Teach. 44, 301-303 (May 2006).

11. K. P. Brown and P. W. Laws, "Exploring the greenhouse effect through physics-oriented activities," Phys. Educ. 38, 115-122 (March 2003).

12. P. Heller and M. Hollabaugh, "Teaching problem solving through cooperative grouping Part 2: Designing problems and structuring groups," Am. J. Phys. 60, 637-644 (July 1992).

13. W. K. Adams, K. K. Perkins, N. S. Podolefsky, M. Dubson, N. D. Finkelstein, and C. E. Wieman, "New instrument for measuring student beliefs about physics and learning physics: The Colorado Learning Attitudes about Science Survey," Phys. Rev. ST Phys. Educ. Rev. 2, 10101 (2006); www.colorado.edu/sei/class/.

14. Likert questions ask students to indicate their level of agreement or disagreement to a statement on a multi-point scale.

The CLASS questions are of the following format: Choose one of the above five choices that best expresses your feeling about the statement. If you don't understand a statement, leave it blank. If you have no strong opinion, choose Neutral.

"I think about the physics I experience in everyday life."

Strongly Agree / Agree / Neutral / Disagree /

Strongly Disagree

15. E. F. Redish, J. M. Saul, and R. N. Steinberg, "Student expectations in introductory physics," Am. J. Phys. 66, 212-224 (March 1998).

16. W. K. Adams, Development of a Problem Solving Evaluation Instrument; Untangling of Specific Problem Solving Skills, $\mathrm{PhD}$ dissertation, University of Colorado, 2007 (unpublished).
Sandy Martinuk is a PhD student in the Department of Physics and Astronomy at UBC, and will be its first student to earn a PhD for conducting research in physics education. He assisted the faculty in developing and monitoring the innovations to Physics 100, and trained and mentored the teaching assistants.

Department of Physics and Astronomy, 6224 Agricultural Road, University of British Columbia, Vancouver, BC, Canada, V6T 121; sandy.martinuk@gmail.com

Rachel F. Moll is currently a PhD candidate in science education and participated as a graduate research assistant on this collaborative project between the Faculty of Education and the Department of Physics and Astronomy at the University of British Columbia.

Department of Curriculum and Pedagogy, 2125 Main Mall, University of British Columbia, Vancouver, BC, Canada, V6T 1Z4; rfmoll@gmail. com

Andrzej Kotlicki is on faculty in the Department of Physics and Astronomy at UBC and was head instructor for the Physics 100 course from 2005 to 2008. He also had the lectures for one section of students and supervised some labs and tutorials.

Department of Physics and Astronomy, 6224 Agricultural Road, University of British Columbia, Vancouver, BC, Canada, V6T 1Z1; kotlicki@phas.ubc.ca 